\title{
The Behaviour of Superalloys in Marine Gas Turbine Engine Conditions
}

\author{
I. Gurrappa ${ }^{*}$, I. V. S. Yashwanth' ${ }^{2}$ A. K. Gogia ${ }^{1}$ \\ ${ }^{1}$ Defence Metallurgical Research Laboratory, Kanchanbagh PO, Hydereabad; ${ }^{2}$ M.V.S.R. Engineering College, Nadargul, Hyderabad, \\ India. \\ Email: *igp1@rediffmail.com
}

Received July 19 ${ }^{\text {th }}$, 2011; revised August 25 $5^{\text {th }}, 2011$; accepted September $8^{\text {th }}, 2011$.

\begin{abstract}
This paper presents hot corrosion results carried out systematically on the selected nickel based superalloys such as IN 738 LC, GTM-SU-718 and GTM-SU-263 for marine gas turbine engines both at high and low temperatures that represent type I and type II hot corrosion respectively. The results were compared with advanced superalloy under similar conditions in order to understand the characteristics of the selected superalloys. It is observed that the selected superalloys are relatively more resistant to type I and type II hot corrosion when compared to advanced superalloy. In fact, the advanced superalloy is extremely vulnerable to both types of hot corrosion. Subsequently, the relevant reaction mechanisms that are responsible for slow and faster degradation of various superalloys under varied hot corrosion conditions were discussed. Based on the results obtained with different techniques, a degradation mechanism for all the selected superalloys as well as advanced superalloy under both types of hot corrosion conditions was explained. Finally, the necessity as well as developmental efforts with regard to smart corrosion resistant coatings for their effective protection under high temperature conditions was stressed for their enhanced efficiency.
\end{abstract}

Keywords: Marine Gas Turbines, Superalloys, Hot Corrosion, Degradation Mechanism, Smart Coatings

\section{Introduction}

Improved efficiency is the requirement for all types of modern gas turbines. In particular, achieving enhanced efficiency for marine gas turbines is a major challenge as the surrounding environment is highly aggressive. This aspect depends not only on the design but also on the selection of appropriate materials for their construction. Between the two, selection of materials plays a vital role as the materials have to perform well for the designed period under severe marine environmental conditions. Hot corrosion in a marine environment causes the materials to degrade at a significantly faster rate and causes catastrophic failures. It is important to mention that hot corrosion becomes a limiting factor for the life of components in marine gas turbines. Hence, the focus is on selection of appropriate materials and coatings.

Therefore, advanced materials with considerably improved properties are essential in order to enhance the efficiency of modern gas turbine engines. Efforts made in this direction made it possible to develop an advanced superalloy which exhibits excellent high temperature strength properties [1]. Application of high performance protective coatings over the conventional superalloys is an alternative approach to enhance the efficiency. As mentioned above, the issue is complicated for marine applications by the aggressivity of the environment [2-4]. Thus, the hot corrosion resistance of superalloys is as important as their high temperature strength in gas turbine engine applications [5-11]. An exhaustive review with recent developments as well as fundamentals of hot corrosion in gas turbine engines is available elsewhere [12].

Systematic studies were carried out on the selected superalloys in marine environments and at different elevated temperatures, which simulates the marine gas turbine engines. Comparative studies with an advanced superalloys were also carried out under similar environmental conditions in order to determine the nature of degradation and to establish the possible reaction mechanisms that cause the selected superalloys to corrode under marine environmental conditions before suggesting suitable high performance protective coatings for their effective protection.

\section{Experimental}

The selected superalloys for the present investigation are presented in Table 1. It is to be noted that the selected 
Table 1. The chemical composition of selected superalloys (wt\%).

\begin{tabular}{|c|c|c|c|c|c|c|c|c|c|c|c|c|c|c|}
\hline Superalloy & $\mathrm{Ni}$ & $\mathrm{Cr}$ & Co & W & $\mathrm{Al}$ & Ta & $\mathrm{Ti}$ & Mo & Re & $\mathrm{Hf}$ & $\mathrm{Fe}$ & Mn & $\mathrm{Si}$ & $\mathrm{Cu}$ \\
\hline GTM-SU-263 & Bal & 20 & 20 & - & 0.6 & 1.3 & 2.4 & 6.0 & - & - & 0.7 & 0.6 & 0.4 & 0.2 \\
\hline GTM-SU-718 & 52.5 & 18.5 & 9.0 & 6.0 & 0.5 & 6.5 & 0.9 & 3.0 & - & - & 19.0 & 0.2 & 0.2 & $5.1 \mathrm{Nb}$ \\
\hline IN 738 LC & Bal & 16 & 8.5 & 2.6 & 3.4 & 8.5 & 3.4 & 1.75 & - & - & - & 0.2 & 0.3 & $0.9 \mathrm{Nb}$ \\
\hline Advanced alloy & Bal & 2.9 & 7.9 & 5.8 & 5.6 & 8.5 & - & - & 6.5 & 0.1 & - & - & - & - \\
\hline
\end{tabular}

superalloys contain no rhenium but sufficient amount of chromium, while newly developed alloys contains about $6.5 \%$ rhenium and a very small amount of chromium. The modified chemistry with high contents of rhenium and tantalum makes the advanced superalloys to exhibit very good high temperature strength properties [1]. Small discs of about $3 \mathrm{~mm}$ thick were cut from all the superalloys, grounded up to 600 grit surface finish and cleaned with distilled water followed by acetone. Subsequently, the hot corrosion studies were carried out by a salt coating test, in which the specimens were coated with chloride and vanadium containing salts prior to hot corrosion studies at $900^{\circ} \mathrm{C}$ and $700^{\circ} \mathrm{C}$, which represents type I and II hot corrosion respectively. Hot corrosion tests were also carried out at $800^{\circ} \mathrm{C}$. The weight change data was recorded initially after 3 hours and later for every 20 hours. Each time, the specimens were washed with hot distilled water, dried and then recorded the weight. After recording the weight, the specimens were re-coated each time with the salt mixture and hot corrosion studies were carried out for a total period of 100 hours.

After completion of hot corrosion tests, the specimens were examined for surface morphology with Scanning Electron Microscope (SEM) and the corrosion products were analyzed by Electron Dispersive Spectroscopy (EDS) and X-ray diffraction techniques. Cross sections of all the corroded specimens were analyzed for understanding the effect of hot corrosion and then elemental distribution was determined in order to evolve their degradation mechanisms.

\section{Results and Discussion}

Figures 1, 2 and $\mathbf{3}$ show as hot corroded superalloys in chloride as well as vanadium containing environments under type I and type II hot corrosion conditions. As can be seen, all the selected superalloys were severely corroded at both the temperatures and environments. The corrosion is more severe under type I when compared to type II conditions in the both the environments. It indicates that all the superalloys are highly susceptible to hot corrosion. It is important to notice that the advanced superalloy is more vulnerable to hot corrosion (Figure 4) even under type II hot corrosion conditions i.e. at $700^{\circ} \mathrm{C}$. Of course, the corrosion is much severe under type I
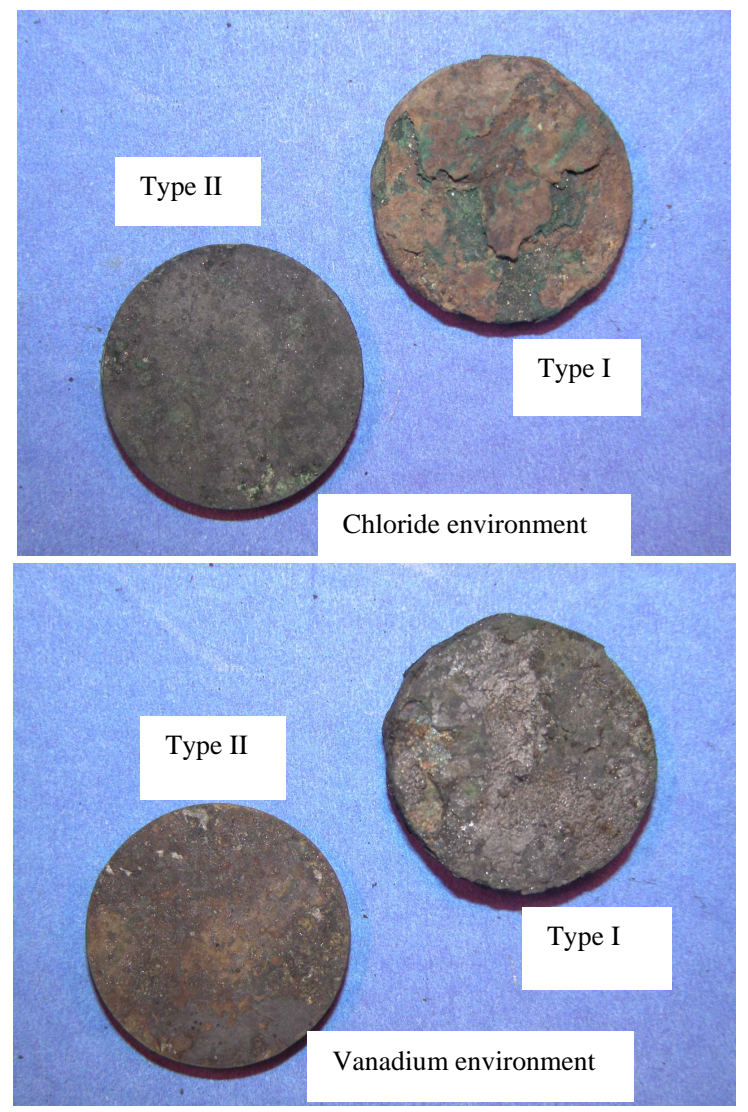

Figure 1. As hot corroded superalloy GTM-SU-263 in chloride and vanadium containing environments under type I and type II conditions.

conditions i.e. $900^{\circ} \mathrm{C}$. The advanced alloy degrades at a very faster rate making it difficult to recognize over a period of time as evidenced from the experiments. It is clearly indicating that the modified chemistry of the advanced superalloy could not improve its hot corrosion resistance. However, it exhibits very good high temperature strength characteristics. Whereas other selected superalloys exhibits relatively better hot corrosion resistance both under type I and type II conditions and their high temperature strength is less when compared to the advanced superalloy.

Figure 5 demonstrates the weight change data for all the selected superalloys at $800^{\circ} \mathrm{C}$ for a period of 100 hours. The data revealed that all the superalloys were 


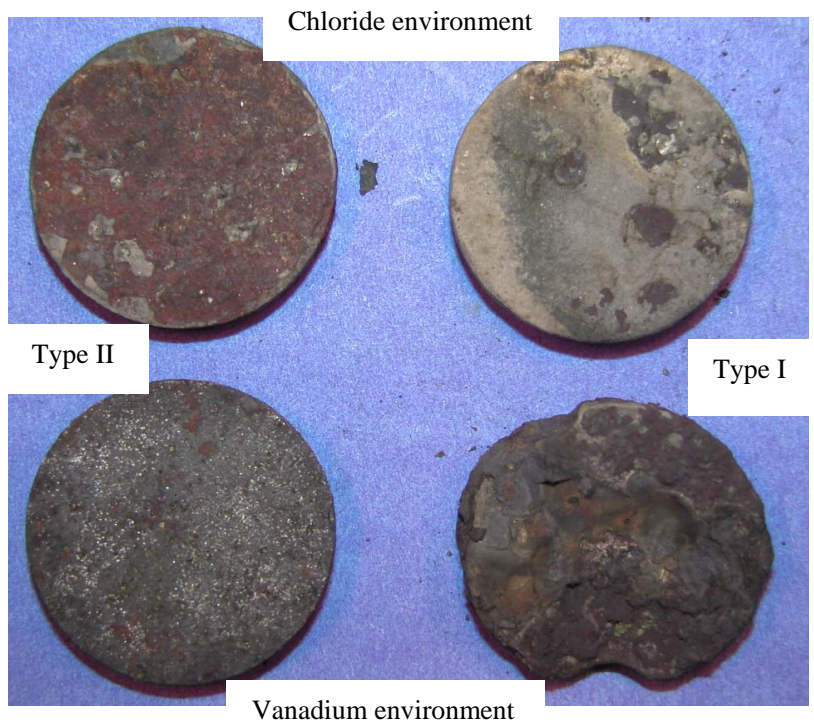

Figure 2. As hot corroded superalloy GTM-SU-718 in chloride and vanadium containing environments under type $I$ and type II conditions.

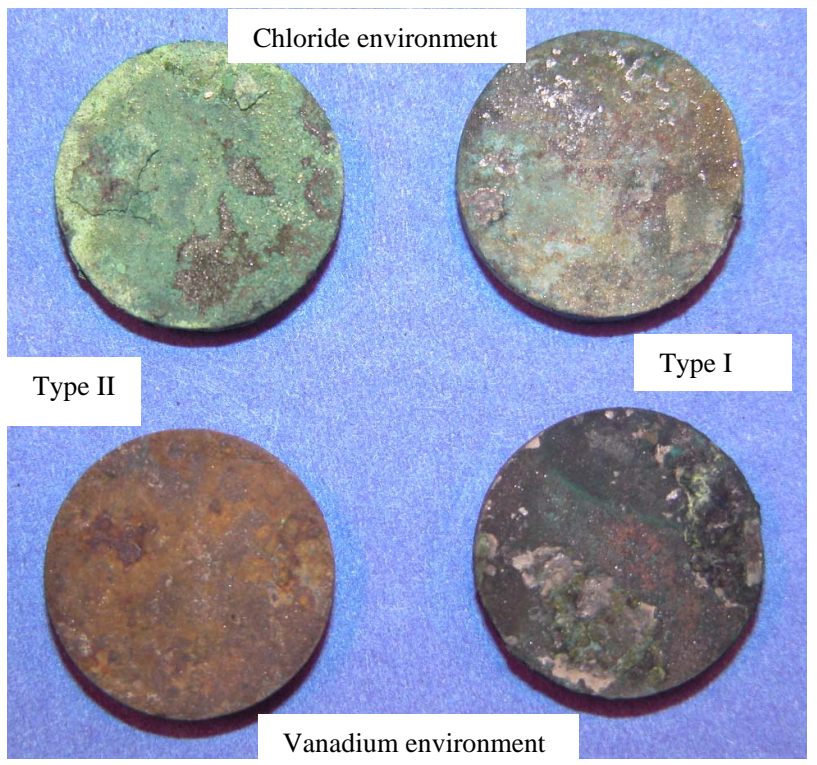

Figure 3. As hot corroded superalloy IN 738 LC in chloride and vanadium containing environments under type $I$ and type II conditions.

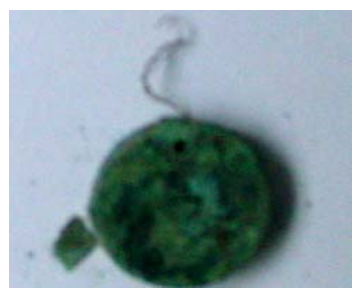

Figure 4. As hot corroded advanced superalloy in chloride containing environments under type II conditions.

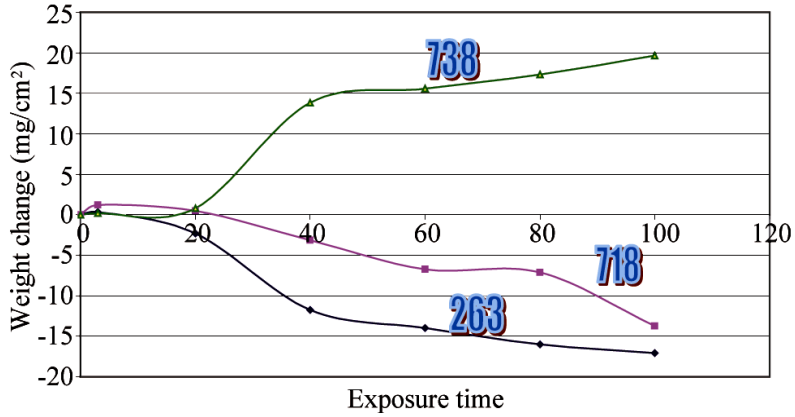

Figure 5. Weight change data for different superalloys at $800^{\circ} \mathrm{C}$ in vandium environment.

followed the same trend up to 20 hours and thereafter IN 738 LC superalloy forms the scale at a steady rate while other two superalloys form thicker scales and spalled subsequently. This behavior is same for every cycle and entire exposure period. The results obtained at other studied temperatures like $700^{\circ} \mathrm{C}$ and $900^{\circ} \mathrm{C}$ in both the environments exhibited similar behavior. It is clearly indicating that all the superalloys are not resistance to hot corrosion at all the temperatures in both the environments.

The surface morphologies of all the selected superalloys as well as advanced superalloy were studied and typical morphology of advanced superalloy at $900^{\circ} \mathrm{C}$ is presented in Figure 6. The surface morphology is different for different superalloys under the selected environmental conditions. EDS measurements revealed that the corrosion products contain sulphides and oxides of nickel and alloying elements of superalloys like $\mathrm{Co}, \mathrm{Cr}, \mathrm{W}, \mathrm{Ti}$, $\mathrm{Ta}$, Re etc. The cross sections of hot corroded superalloys revealed that the corrosion-affected zone is large for all the superalloys. Among them, the affected zone is more for the advanced superalloy indicating that severe corrosion took place during the hot corrosion process for the advanced superalloy when compared to other selected superalloys (Figure 6).

The elemental distributions of all hot corroded superalloys including the advanced superalloy were studied in detail and typical elemental distribution of advanced superalloy at 900 and $700^{\circ} \mathrm{C}$ are illustrated in Figures 7 and 8 respectively. In case of selected superalloys for marine gas turbines, which contains good amount of chromium could form continuous chromia scale on their surface. Particularly, for IN 738 LC, the continuous and protective chromia was clearly visible. They also promoted alumina as well as titania scales. However, diffusion of sulphur and oxygen into the superalloys was clearly observed. While SU 263 and 718, that contain less chromium could not form continuous chromia scale. Thin alumina scale was observed on the surface of superalloys. Small amounts of sodium and chlorine were also present 


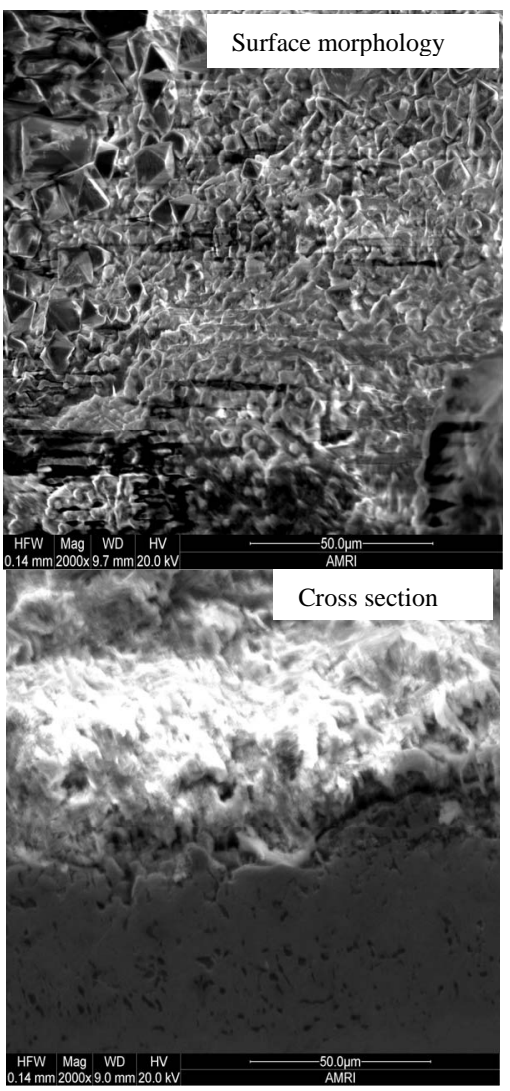

Figure 6. Surface morphology and cross section of advanced superalloy after type I hot corroison in chloride environment.

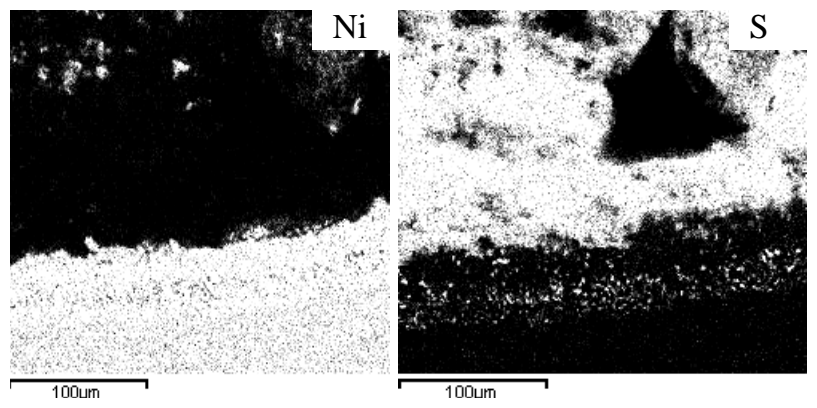

Figure 7. Elemental distribution of an advanced superalloy after hot corrosion at $900^{\circ} \mathrm{C}$ for 80 hours.

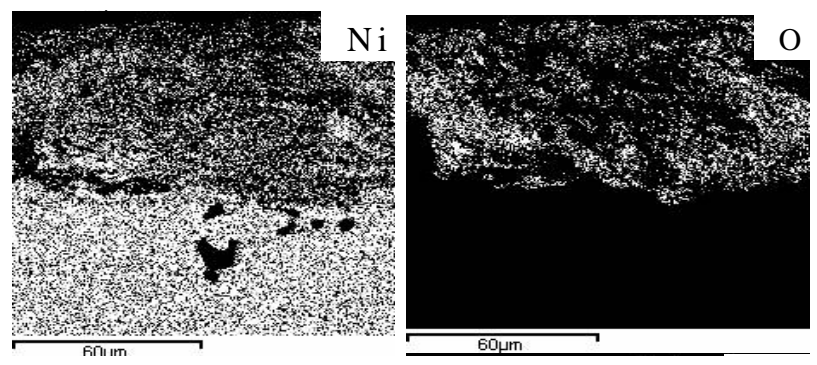

Figure 8. Elemental distribution of an advanced superalloy after hot corrosion at $700^{\circ} \mathrm{C}$ for 80 hours. in the corrosion products but not diffused into the superalloys. However, diffusion of sulphur and oxygen into the superalloys was noticed.

The elemental distribution of hot corroded advanced superalloy at $900^{\circ} \mathrm{C}$ and $700^{\circ} \mathrm{C}$ showed extensive presence of oxygen, sulphur and sodium in the corrosion products. Considerable diffusion of sulphur into the superalloy was clearly observed at $900^{\circ} \mathrm{C}$ (Figure 7) while oxygen at $700^{\circ} \mathrm{C}$ (Figure 8). Rhenium and tungsten were present in the corrosion products at $900^{\circ} \mathrm{C}$ and they were present in the corrosion affected zone of advanced superalloy that was hot corroded at $700^{\circ} \mathrm{C}$. Ta and $\mathrm{Hf}$ were seen in the corrosion affected region. It is important to mention here that neither alumina nor chromia formation was observed on the superalloy. It is due to the fact that chromium content in the adavanced superalloy is considerably low. At the same time, other alloying elements could not form any protective oxide scales. In essence, it is concluded that the advanced superalloy is highly susceptible to hot corrosion, though it exhibits excellent high temperature strength properties. It is important to mention here that the selected superalloys are also vulnerable to both types of hot corrosion but the intensity of attack is less. Among the selected superalloys, the IN 783 LC is more resistant while SU 263 is moderate and SU 718 is more susceptible. It clearly stresses the need to apply high performance protective coatings for their protection against hot corrosion both at low and high temperatures i.e. type II and type I as the marine gas turbine engines encounter both the problems during service. The protective coatings allow the marine gas turbine engines to operate at varied temperatures and enhance their efficiency by eliminating failures during service.

In essence, the present results clearly revealed that the selected superalloys as well as advanced superalloy are highly vulnerable to hot corrosion. The results further revealed that the advanced superalloy corrodes much faster when compared to selected superalloys. It is attributed to the fact that the tungsten which is the alloying element added along with other alloying elements in order to obtain high temperature strength characteristics of the superalloys, forms acidic tungsten oxide $\left(\mathrm{WO}_{3}\right)$ due to which fluxing of protective oxide scales such as alumina and chromia takes place very easily. This type of acidic fluxing is self-sustaining because $\mathrm{WO}_{3}$ forms continuously that cause faster degradation of superalloys under marine environmental conditions at elevated temperatures. The degradation mechanism is explained in two steps as follows:

a) The tungsten present in the superalloys reacts with the oxide ions present in the environment and forms tungsten ion

$$
\mathrm{WO}_{3}+\mathrm{O}^{2-}=\mathrm{WO}_{4}^{2-}
$$


b) As a result, the oxide ion activity of the environment decreases to a level where acidic fluxing reaction with the protective alumina and chromia can occur

$$
\begin{aligned}
& \mathrm{Al}_{2} \mathrm{O}_{3}=\mathrm{Al}^{3+}+\mathrm{O}^{2-} \\
& \mathrm{Cr}_{2} \mathrm{O}_{3}=\mathrm{Cr}^{3+}+\mathrm{O}^{2-}
\end{aligned}
$$

A similar reaction mechanism occurs if the superalloys contain other refractory elements like vanadium and molybdenum.

The following section describes an electrochemical phenomenon that explains the selected superalloys as well as advanced superalloy degradation process in detail under hot corrosion conditions:

Hot corrosion of all superalloys take place by oxidation of base as well as alloying elements like nickel, cobalt, chromium, aluminium, tantalum, rhenium etc. at the anodic site and forms $\mathrm{Ni}^{2+}, \mathrm{Co}^{3+}, \mathrm{Cr}^{3+}, \mathrm{Al}^{3+}, \mathrm{Re}^{4+}$, $\mathrm{Ta}^{5+}$ ions etc. while at the cathodic site, $\mathrm{SO}_{4}{ }^{2-}$ reduces to $\mathrm{SO}_{3}{ }^{2-}$ or $\mathrm{S}$ or $\mathrm{S}^{2-}$ and oxygen to $\mathrm{O}^{2-}$. Since the metal ions i.e. $\mathrm{Ni}^{2+}, \mathrm{Co}^{3+}, \mathrm{Cr}^{3+}, \mathrm{Al}^{3+}, \mathrm{Re}^{4+}, \mathrm{Ta}^{5+}$ ions etc. are unstable at the elevated temperature and therefore reacts with the sulphur ions to form metal sulphides. The metal sulphides can easily undergo oxidation at elevated temperatures and form metal oxides by releasing free sulphur $\left(\mathrm{MS}+1 / 2 \mathrm{O}_{2}=\mathrm{MO}+\mathrm{S}\right)$. As a result, sulphur concentration increases at the surface of superalloys and enhances sulphur diffusion into them and form sulphides inside the superalloys. The practical observation of sulphides in hot corroded superalloys specimens clearly indicates that the

electrochemical reactions took place during their hot corrosion process. Simultaneously, the metal ions react with oxide ions that are evolved at the cathodic site leading to the formation of metal oxides. The metal oxides dissociate at elevated temperatures to form metal ions and oxide ions. As a result, oxygen concentration increases at the surface and thereby diffuses into the superalloys. Practical observation of oxides in hot corroded superalloys specimens is a clear indication that the electrochemical reactions took place during the hot corrosion process.

Therefore, the hot corrosion of all the alloys i.e. selected and advanced superalloy, is electrochemical in nature and the relevant electrochemical reactions are shown below:

At the anode

$$
\begin{aligned}
& \mathrm{Ni}=\mathrm{Ni}^{2+}+2 \mathrm{e}^{-} \\
& \mathrm{Cr}=\mathrm{Cr}^{3+}+3 \mathrm{e}^{-} \\
& \mathrm{Co}=\mathrm{Co}^{3+}+3 \mathrm{e}^{-} \\
& \mathrm{Al}=\mathrm{Al}^{3+}+3 \mathrm{e}^{-} \\
& \mathrm{Re}=\mathrm{Re}^{4+}+4 \mathrm{e}^{-} \\
& \mathrm{Ta}=\mathrm{Ta}^{5+}+5 \mathrm{e}^{-}
\end{aligned}
$$

etc.

Figure 9 illustrates an electrochemical model showing that all the studied superalloys degradation is electrochemical in nature. Similar mechanism is applicable to other superalloys and their families.

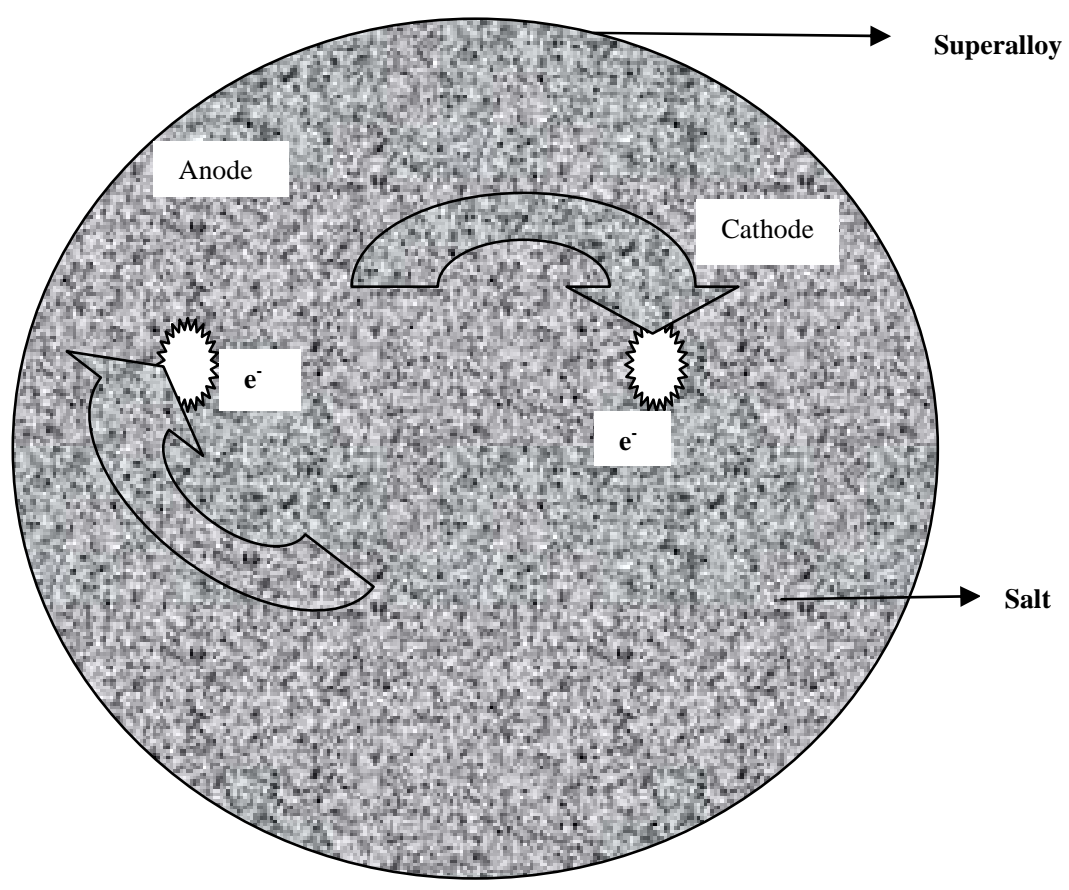

Figure 9. An electrochemical model showing the hot corrosion of selected and advanced superalloys is an electrochemical process. 
The template is used to format your paper and style the text. All margins, column widths, line spaces, and text fonts are prescribed; please do not alter them. You may note peculiarities. For example, the head margin in this template measures proportionately more than is customary. This measurement and others are deliberate, using specifications that anticipate your paper as one part of the entire proceedings, and not as an independent document. Please do not revise any of the current designations.

\section{Design and Development of Smart Coatings}

Recent extensive research has resulted in design and development of smart coatings which provide effective protection to the superalloy blades for the designed period against type I and type II hot corrosion that are normally encountered in marine and industrial gas turbine engines which in turn enhances their efficiency considerably $[13,14]$. The same coating can be applied to aero gas turbine engine components due the fact that hot corrosion is a concern when they move at low altitudes across the sea and provide total protection. This is a major developmental work in the area of gas turbine engines used in aero, marine and industrial applications. Unlike the conventional/existing coatings, the smart coatings provide total protection to the superalloy components used in aero, marine and industrial applications by forming appropriate protective scales depending on the surrounding environmental conditions [12-14].

\section{REFERENCES}

[1] N. Das, US patent 5,925,198, July 1999

[2] M. R. Khajavi and M. H. Shariat, "Failure of First Stage Gas Turbine Blades,” Engineering Failure Analysis, Vol. 11, No. 4, 2004, pp. 589-597. doi:10.1016/j.engfailanal.2003.08.010

[3] J. M. Gallardo, J. A. Rodrigue and E. J. Herrera, "Failure of Gas Turbine Blades,” Wear, Vol. 252, No. 3-4, 2002, pp. 264-268. doi:10.1016/S0043-1648(01)00885-7
[4] N. Eliaz, G, Shemesh and R. M. Latarision, "Hot Corrosion in Gas Turbine Components," Engineering Failure Analysis, Vol. 9, No. 1, 2002, pp. 31-43. doi:10.1016/S1350-6307(00)00035-2

[5] M. Konter and M. Thumann, "Materials and Manufacturing of Advanced Industrial Gas Turbine Components," Journal of Materials Processing Technology, Vol. 117, No. 3, 2001, pp. 386-390. doi:10.1016/S0924-0136(01)00785-3

[6] J. Stringer, "High Temperature Corrosion of Superalloys,” Materials Science and Technology, Vol. 3, 1987, pp. 482-493

[7] A. S. Radcliff, "Factors Influencing Gas Turbine Use and Performance,” Materials Science and Technology, Vol. 3, 1987, pp. 554-561

[8] R. F. Singer, "New Materials for Industrial Gas Tubines,” Materials Science and Technology, Vol. 3, 1987, pp. 726732

[9] I. Gurrappa, "Hot Corrosion Behaviour of CM 247 LC Alloy in $\mathrm{Na}_{2} \mathrm{SO}_{4}$ and $\mathrm{NaCl}$ Environments," Oxidation of Metals, Vol. 51, No. 5-6, 1999, pp. 353-382. doi:10.1023/A:1018831025272

[10] C. J. Wang and J. H. Lin, "The Oxidation of MAR M247 Superalloy with $\mathrm{Na}_{2} \mathrm{SO}_{4}$ Coating," Materials Chemistry and Physics, Vol. 76, No. 2, 2002, pp. 123-129. doi:10.1016/S0254-0584(01)00527-2

[11] I. Gurrappa and A. S. Rao, "Thermal Barrier Coatings for Enhanced Efficiency of Gas Turbine Engines,” Surface and Coating Technology, Vol. 201, No. 6, 2006, pp. 30163029. doi:10.1016/j.surfcoat.2006.06.026

[12] I. Gurrappa, I. V. S. Yashwanth, A. K. Gogia, H. Murakami and S. Kuroda, Interlational Materials Revews. (In Press)

[13] I. Gurrappa, "Identification of a Smart Bond Coating for Gas Turbine Engine Applied Lications,” Journal of Coating Technology Research, Vol. 5, No. 3, 2008, pp. 385390. doi:10.1007/s11998-008-9103-y

[14] I. Gurrappa, "Final Report on Design and Development of Smart Coatings for Aerospace Applied Lications," European Commission, July 2008 